\title{
nature
}

physics

\section{The oxygen of publicity}

\author{
The Large Hadron Collider launched in a blaze of publicity. But, amid claims that the machine \\ would destroy the Earth, is all publicity good publicity?
}

You couldn't have missed it. On 10 September, the world held its breath as the button was pushed on the Large Hadron Collider at CERN. The start-up went like a dream - after less than an hour of operation, the first proton beam had completed a lap of the $27-\mathrm{km}$ collider. Later that day, a second beam was circulated in the opposite direction. These are the first, gradual steps towards the collision of beams, then collisions at high energies, once the accelerating power of the LHC is unleashed.

Media coverage of the event was huge, although not unprecedented: probably the last time science basked in such attention was, however, back at the time of the Apollo Moon landings, in 1969. But, although there were commendable attempts to discuss the real aims of the LHC project, most column inches and airtime were given over to the perceived threat that the collision of $7-\mathrm{TeV}$ protons inside the LHC could result in the destruction of the planet.

That's not without precedent either. The launch in 1999 of the Relativistic Heavy Ion Collider at Brookhaven National Laboratory provoked headlines such as "Big Bang machine could destroy Earth". This time around, fuelled by the filing of a US lawsuit and of a request for an emergency injunction to the European Court of Human Rights (which was rejected), the doomsday message was spread farther and wider.

CERN has taken the correct tack in patiently refuting claims of impending disaster (as have, probably, most physicists over the past weeks, fielding enquiries from worried friends and family), on the basis of careful scientific investigation of the possibilities. There's little else that could have been done. The

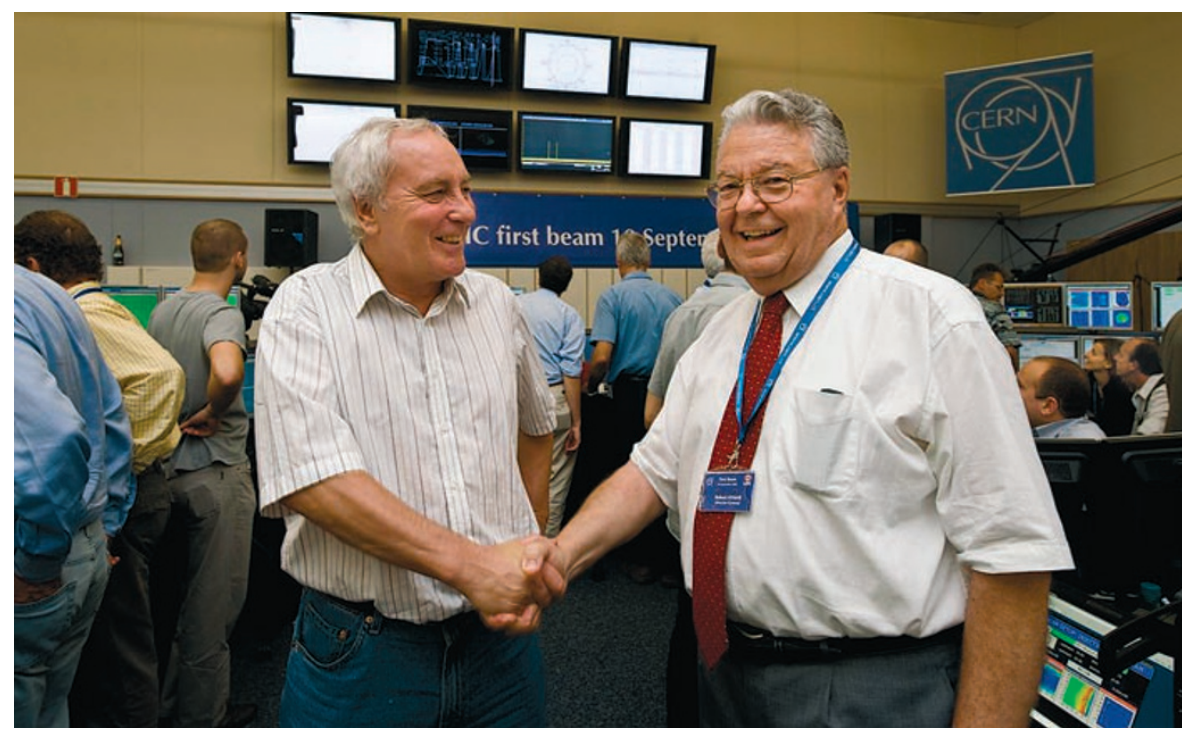

CERN Director General Robert Aymar (right) congratulates LHC Project Leader Lyn Evans on a seamless start-up.

level of genuine concern raised among the public was undesirable and regrettable but unavoidable.

The outcome, when the world as we know it didn't end with the first circulating beam, could well prove more positive. The world is aware of the LHC, and there is work to do to sustain that awareness and ensure that the public (and governments) are engaged with the results of the experiment, when they arrive.

But the challenge now is to all physicists, not only CERN ones - indeed, it's to all scientists - to capitalize on the attention that the LHC is enjoying. We could see a future generation of scientists, in many disciplines, who cite childhood memories of the LHC as their inspiration, just as the children of the space age point to Sputnik and the Apollo programme as their lead into science and engineering. It's a terrific opportunity to inform, impress and inspire.

The success of the LHC programme, its start-up and the results to come, must not be ignored in the wider physics community; it's not only relevant to particle physics, or to justifying future funding in this one avenue of science. It's big science and with it comes a big opportunity to encourage in governments, in particular, the awareness and recognition of how vitally physics underpins all of the workings of our society. The tremendous level of publicity for the launch of the LHC could well prove the oxygen of physics. 